\title{
Response to "Attributional life cycle assessment: is a land-use baseline necessary?"- appreciation, renouncement, and further discussion
}

\author{
Matthew Brander ${ }^{1}$ \\ Received: 25 August 2015 / Accepted: 25 September 2015 /Published online: 15 October 2015 \\ (C) The Author(s) 2015. This article is published with open access at Springerlink.com
}

\begin{abstract}
Purpose Soimakallio et al. (Int J Life Cycle Assess 20(10):1364-1375, 2015) establish the need for baselines in attributional life cycle assessment (LCA) and thereby provide an important milestone in the evolving conceptualisation of both attributional and consequential LCA. The purpose of this commentary is to acknowledge Soimakallio et al.'s contribution, identify its implications for a number previously published papers, critique the use of natural regeneration baselines, and offer some further thoughts on the conceptual nature of attributional and consequential approaches.

Methods The methods used in this study were comparative analysis with other forms of attributional inventory and an illustrative example of alternative 'natural' baselines for carbon sequestration.

Results and discussion The commentary concurs that attributional LCA requires baselines and that attributional studies are not inventories of absolute emissions and removals, contrary to previous statements by the present author. Nevertheless, a number of previous statements on attributional and consequential methods remain largely unchanged: attributional studies can be aggregated to approximate total (anthropogenic) environmental impacts; substitution is conceptually inappropriate for attributional LCA; and the attributional-consequential distinction can be applied to other forms of environmental assessment such as national, corporate, and community greenhouse gas inventories
\end{abstract}

Responsible editor: Mary Ann Curran

Matthew Brander

Matthew.Brander@ed.ac.uk

1 University of Edinburgh Business School, 29 Buccleuch Place, Edinburgh EH8 9JS, UK (attributional), and project and policy-level greenhouse gas assessments (consequential). A further finding is that natural regeneration baselines may not be appropriate for attributional studies and that some arguments in their favour may be symptomatic of a misconception of attributional LCA.

Conclusions Soimakallio et al. (Int J Life Cycle Assess 20(10):1364-1375, 2015) make an extremely useful contribution to the evolving conceptualisation of attributional and consequential approaches, which is highly important for methodological development and choosing the appropriate method for a given purpose.

Keywords Attributional life cycle assessment · Baselines · Consequential life cycle assessment · Decision-making · National greenhouse gas inventories · Sequestration · Substitution

\section{Introduction}

There is a lively and on-going debate within the life cycle assessment (LCA) community on the conceptual nature and relative merits of attributional and consequential LCA (Plevin et al. 2014a; Brandão et al. 2014; Hertwich 2014; Suh and Yang 2014; Anex and Lifset 2014; Dale and Kim 2014; Plevin et al. 2014a, 2014b, 2014c). Clarifying the conceptual nature of these methods is highly important as it directly affects methodological issues, e.g. whether substitution should be used in attributional LCA, and the appropriate use of each approach, e.g. whether attributional LCA is sufficient to support decision-making.

The LCA community has a strong track record in conceptual debate and innovation, exemplified, not least, by the development of the attributional-consequential distinction itself (Curran et al. 2005). It is also worth noting that such 
innovations can be highly relevant and useful to other fields of environmental accounting beyond LCA (Brander 2015), and this enhances the significance of the debate further. Soimakallio et al. (2015) is an important milestone in the evolving conceptualisation of attributional and consequential methods, and although the analysis presented below finds both agreement and disagreement with different aspects of the paper, all aspects help to bring further clarity to the conceptual nature of the attributional-consequential distinction.

The focus of the present paper is on greenhouse gas emissions, but the discussion applies equally to any other environmental flow or impact category.

\section{Agreement on attributional baselines}

Soimakallio et al.'s assertion that a baseline is needed in attributional LCA in order to separate out anthropogenic activities (the technosphere) from natural or nonanthropogenic processes (the ecosphere) appears to be fundamentally correct, i.e. it is not possible to achieve this separation without the use of a baseline. Additional support for this assertion can be provided through a comparison with national greenhouse gas inventories under the United Nations Framework Convention on Climate Change (UNFCCC) (United Nations 1992), which may be characterised as another form of attributional account (Brander 2015). National greenhouse gas inventories are inventories of anthropogenic emissions and removals, and baselines are used, albeit implicitly, to separate out anthropogenic from non-anthropogenic emissions/removals. For example, the 'managed land proxy' assumes that all emissions/removals on unmanaged land would occur anyway in nature, i.e. they are part of the non-anthropogenic baseline (Penman et al. 2006; WRI 2014b). If the use of such baselines is appropriate for attributional national greenhouse gas inventories, it can be inferred that they are similarly appropriate for attributional LCA.

Soimakallio et al. (2015) are also entirely correct to conclude that because of the use of baselines, attributional LCAs are not inventories of absolute (observable) emissions and removals, contrary to previous statements made by the present author (Brander et al. 2009; Brander and Wylie 2011; Brander 2015). Soimakallio et al. (2015) also correctly diagnose one of the reasons for conceptualising attributional methods as inventories of absolute impacts, i.e. natural baseline emissions from fossil fuel combustion are generally zero, and therefore, anthropogenic and absolute emissions will tend to be identical. The correct conceptualisation of attributional methods should be as inventories of anthropogenic environmental impacts relative to a natural baseline, rather than absolute environmental impacts.

\section{Scope of renouncement}

Although the characterisation of attributional methods as inventories of absolute environmental impacts should be renounced, it is important to note that a number of previous statements on the conceptual nature of attributional and consequential approaches require only slight restatement or remain unaffected.

Firstly, the idea that "[attributional] LCA results of all the products in the world should add up to the total environmental impact in the world" (Tillman 2000, pp. 116-117)) remains true, though it must be clarified that the total is for total anthropogenic impacts and not total absolute impacts. The truth of this idea can also be seen by considering the aggregation of all national greenhouse gas inventories, which, in principle, approximate to total global anthropogenic emissions and removals (excepting ad hoc exclusions such as international aviation and shipping, military activities etc.). This conception of attributional methods is also consistent with the idea that attributional LCA attributes "portions of the total pollution and resource consumption flows occurring from the economy as it is at a given point in time to each existing product life cycle" (Soimakallio et al. 2015).

Secondly, the inappropriateness of substitution as a methodological technique within attributional LCA remains true (Brander and Wylie 2011). The baseline used in attributional LCA is for non-anthropogenic environmental impacts, for the purpose of separating out anthropogenic from nonanthropogenic impacts. In contrast, the baseline implicit within the technique of substitution is for alternative product systems (i.e. anthropogenic systems) which are displaced by the co-products or multiple functions of the system studied. If substitution is used in attributional LCA, it will not provide an inventory of anthropogenic environmental impacts relative to a natural baseline (and in addition, the sum of all attributional LCAs will not approximate to total anthropogenic impacts).

Thirdly, the categorisation of all existing greenhouse gas accounting methods as either attributional or consequential in Brander (2015) remains unchanged. National greenhouse gas inventories (Penman et al. 2006), corporate inventories (WBCSD/WRI 2004; ISO 2006a), and community inventories (Schultz et al. 2014; British Standards Institute 2013) are all inventories of anthropogenic emissions and removals (i.e. they are attributional), and project (WBCSD/WRI 2005; ISO 2006b) and policy-level (WRI 2014a) accounting both aim to quantify the total system-wide change in emissions caused by a given decision or action (i.e. they are consequential). Recognition of these 'families' of methods, with shared conceptual underpinnings, is useful for transposing methodological innovations and practices between methods. For example, the use of non-anthropogenic baselines within national greenhouse gas inventories under the UNFCCC appears to be relatively limited, i.e. to the treatment of emissions/removals from 
unmanaged land (though guidance for Kyoto Protocol reporting contains other instances of baselines, e.g. natural disturbance baselines for forest land (IPCC 2013)); innovations within ALCA, such as accounting for foregone sequestration on managed land, may also be relevant to national inventories.

\section{Appropriateness of natural regeneration}

Soimakallio et al. (2015) suggest that natural regeneration is the most coherent baseline for attributional LCA; however, the following illustrative example and discussion raise a number of potential problems.

Firstly, consider two of the possible options for the natural baseline for carbon sequestration: (a) the level of sequestration that would have occurred in the absence of all human activity; and (b) the level of sequestration that would occur if all human activity ceased (i.e. natural regeneration). Figure 1 provides a schematic diagram showing these alternative possible natural baselines (with positive sequestration shown as a negative number), as well as terrestrial carbon stocks and emissions from land use change.

To provide a brief description of this illustrative example: (1) At some point in the past terrestrial carbon stocks accumulated as the ecosystem sequestered $\mathrm{CO}_{2}$ from the atmosphere; (2) An equilibrium carbon stock was reached and the rate of on-going natural sequestration declined to zero; (3) Following this, anthropogenic land use change occurred, e.g. forest land was converted to agricultural use; (4) The continued cultivation of the land means that it does not revert to a natural state, and the on-going rate of sequestration remains at zero.

If the 'no human activity existed' baseline is chosen, this has the same level of on-going sequestration as the "with product' scenario (i.e. zero), and so there would be no foregone sequestration from continued land occupation. In contrast, if the 'natural regeneration' baseline is chosen, this indicates an amount of on-going baseline sequestration, and therefore, there will be some foregone sequestration from continued anthropogenic land use. The key question is which is the most appropriate baseline for attributional LCA?

One argument against the 'natural regeneration' baseline is that it is, in fact, an artifice of human activity, i.e. the potential for natural regeneration and on-going sequestration only exists because anthropogenic land use change has reduced terrestrial carbon stocks below their equilibrium level. If attributional LCA is to separate out anthropogenic impacts from background natural flows, then the natural baseline should not itself include anthropogenic activities (such as land use change), or as Soimakallio et al. put it, "including parts of the technosphere in the baseline is against the fundamental purpose of ALCA". Essentially, the natural regeneration baseline is not natural, as it is created by anthropogenic activities. Such a baseline may be appropriate for consequential LCA, where the baseline may include anthropogenic activities (as is the case with the technique of substitution).

A further problem with the natural regeneration baseline is the issue of counting the same foregone sequestration in perpetuity. If the land is maintained in agricultural use, the question of foregone sequestration is ever-present for each successive product-system utilising the land, although the amount of actual foregone sequestration is bounded by the equilibrium carbon stock. Unless there is a way of allocating the foregone sequestration across all future production from the land, the same foregone sequestration may be double-counted ad infinitum. For example, supposing that natural regeneration on an area of land would sequester an average of $1 \mathrm{tCO}_{2}$ per year for 20 years (at which point an equilibrium carbon stock is reached), then products produced from the continued anthropogenic use of the land during those 20 years will incur a
Fig. 1 Two possible options for the natural baseline for carbon sequestration

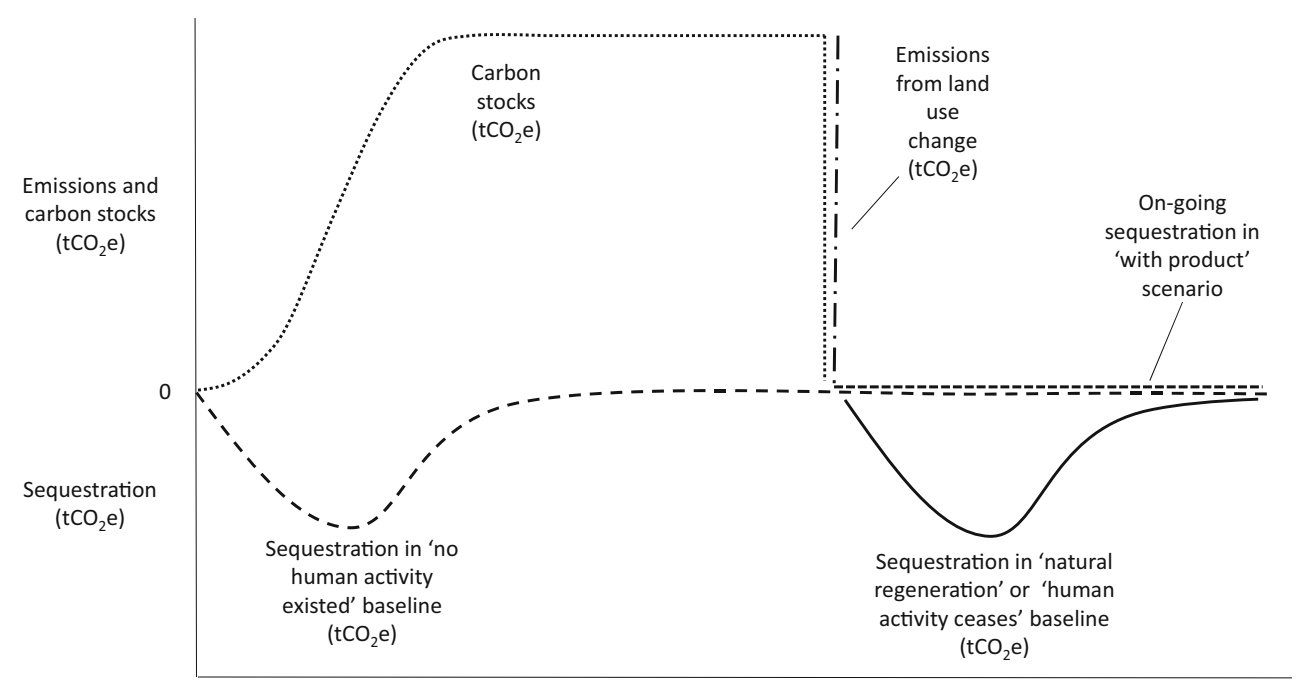


total of $20 \mathrm{tCO}_{2}$ of foregone sequestration. If the products from the next 20 years of continued land use are also allocated $20 \mathrm{tCO}_{2}$ of foregone sequestration, it will be the same $20 \mathrm{tCO}_{2}$ allocated twice, and so on.

One of the arguments cited in favour of a natural regeneration baseline, drawn from Milà i Canals et al. (2007), is that "land occupation postpones natural regeneration of the land, which is an impact that needs to be accounted for" (Soimakallio et al. 2015). Although the postponement of natural regeneration is certainly a consequence of continued land occupation, if it is not an anthropogenic impact relative to a natural baseline (as argued above), then it simply does not belong in an ALCA. There appears to be an impulse to make ALCA capture the total consequences of an activity, possibly in recognition of the principle that decision-making should be based on an understanding of the total consequences of the decision at hand. However, this is properly the purpose of consequential LCA (which captures all impacts by effectively using a baseline that reflects what would happen in the absence of the decision, whether anthropogenic or nonanthropogenic) and not attributional LCA (which only inventories anthropogenic impacts relative to a non-anthropogenic baseline).

A similar misconception may be present in Milà i Canals et al. (2013), where there is concern that attributional LCA results may lead to perverse outcomes, such as incentivising deforestation rather than continued land occupation. However, perverse outcomes are to be wholly expected if attributional LCA is used (on its own) for decision-making, precisely because the method does not necessarily capture the total impacts of the decision at hand (Plevin et al. 2014a). The solution is to recognise that attributional methods, by their very nature, are not sufficient for decision-making (on mitigation actions). In contrast, if a consequential method were used to inform the decision between deforestation and continued land occupation, it would, in theory, identify the option with the lower overall impacts - precisely because the method is intended to capture the total consequences of the decision at hand.

Arguably, the correct use of attributional LCA is for applications such as: assigning responsibility for the on-going management of a set of impacts (e.g. as is the case with national greenhouse gas inventories under the UNFCCC); target setting (e.g., setting percentage reductions relative to a base year inventory); and budgeting for total anthropogenic impacts (e.g., setting carbon budgets to ensure total anthropogenic emissions do not exceed an aggregate threshold (and for this purpose the additivity of attributional inventories, described in Tillman (2000), is essential)). However, it is important to reiterate that any decisions or actions aimed at mitigating inventory impacts or meeting reduction targets should be assessed using consequential methods to avoid unintended consequences which are not captured in the attributional inventory.

\section{Conclusions}

Soimakallio et al. (2015) make an extremely useful contribution to the evolving conceptualisation of attributional and consequential methods, both in terms of what they get right and what may not be entirely right. The proper conceptualisation of attributional and consequential methods is highly important for ensuring that the appropriate method is used for a given purpose. Attributional methods are inventories of anthropogenic impacts relative to a natural baseline and should be used for assigning responsibility for managing those impacts, target setting, and environmental budgeting. However, any mitigation actions must be informed by consequential methods, which seek to describe the total system-wide consequences of the decision at hand. Although this conceptual debate has occurred largely within the field of life cycle assessment, the conceptual apparatus of the attribution-consequential distinction is highly applicable to other forms of environmental accounting, such as national greenhouse gas inventories - which extends the importance of this debate still further.

Acknowledgments Matthew Brander would like to acknowledge the UK's Economic and Social Research Council (ESRC), in partnership with the Society for the Advancement of Management Studies (SAMS) and the UK Commission for Employment and Skills (UKCES), for their support through the Management and Business Development Fellowship Scheme.

Open AccessThis article is distributed under the terms of the Creative Commons Attribution 4.0 International License (http:// creativecommons.org/licenses/by/4.0/), which permits unrestricted use, distribution, and reproduction in any medium, provided you give appropriate credit to the original author(s) and the source, provide a link to the Creative Commons license, and indicate if changes were made.

\section{References}

Anex R, Lifset R (2014) Life cycle assessment: different models for different purposes. J Ind Ecol 18(3):321-323

Brandão $\mathrm{M}$ et al (2014) The use of life cycle assessment in the support of robust (climate) policy making: comment on "Using attributional life cycle assessment to estimate climate-change mitigation...". J Ind Ecol 18(3):461-463

Brander M (2015) Transposing lessons between different forms of consequential greenhouse gas accounting: lessons for consequential life cycle assessment, project-level accounting, and policy-level accounting. J Clean Prod. doi:10.1016/j.jclepro.2015.05.101

Brander M, Wylie C (2011) The use of substitution in attributional life cycle assessment. Greenhouse Gas Meas Manag 1(3-4):161-166

Brander M et al. (2009) Consequential and attributional approaches to LCA : a guide to policy makers with specific reference to greenhouse gas LCA of biofuels. Ecometrica Press, pp.1-14. Available at: http://ecometrica.com/assets//approachesto_LCA3_technical.pdf

British Standards Institute (2013) PAS 2070: 2013. Specification for the assessment of greenhouse gas emissions of a city. British Standards Institute, London

Curran MA, Mann M, Norris G (2005) The international workshop on electricity data for life cycle inventories. J Clean Prod 13(8):853-862 
Dale BE, Kim S (2014) Can the predictions of consequential life cycle assessment be tested in the real world? comment on "Using attributional life cycle assessment to estimate climate-change mitigation...". J Ind Ecol 18(3):466-467

Hertwich E (2014) Understanding the climate mitigation benefits of product systems: comment on "Using attributional life cycle assessment to estimate climate-change mitigation...". J Ind Ecol 18(3):464-465

IPCC (2013) Methods for estimation, measurement, monitoring and reporting of LULUCF activities. In: Hiraishi T et al. (eds) Revised supplementary methods and good practice arising from the Kyoto protocol. IPCC, pp. 1-180. Available at: http://www.ipcc-nggip. iges.or.jp/public/kpsg/

ISO (2006a) ISO 14064-1: 2006 - Specification with guidance at the organization level for quantification and the reporting of greenhouse gas emissions and removals. International Organization for Standardization, Geneva

ISO (2006b) ISO 14064-2: 2006 - Specification with guidance at the project level for quantification, monitoring and reporting of greenhouse gas emission reductions or removal enhancements. International Organization for Standardization, Geneva

Milà i Canals L, Rigarlsford G, Sim S (2013) Land use impact assessment of margarine. Int J Life Cycle Assess 18(6):1265-1277. Available at: http://link.springer.com/10.1007/s11367-012-0380-4. Accessed 17 Aug 2015

Milà i Canals L et al (2007) Key elements in a framework for land use impact assessment within LCA. Int J Life Cycle Assess 12(1):5-15

Penman J et al. (2006) IPCC guidelines for national greenhouse gas inventories 2006. Available at: http://www.ipcc-nggip.iges.or.jp/ public/2006gl/pdf/0_Overview/V0_1_Overview.pdf

Plevin RJ, Delucchi MA, Creutzig F (2014a) Using attributional life cycle assessment to estimate climate-change mitigation benefits misleads policy makers. J Ind Ecol 18(1):73-83
Plevin R, Delucchi M, Creutzig F (2014b) Response to comments on "Using attributional life cycle assessment to estimate climatechange mitigation...". J Ind Ecol 18(3):468-470

Plevin RJ, Delucchi MA, Creutzig F (2014c) Response to "On the uncanny capabilities of consequential LCA" by Sangwon Suh and Yi Yang. Int J Life Cycle Assess 19(8):1559-1560. doi: 10.1007/s11367-014-0739-9

Schultz S et al. (2014) Global protocol for community-scale greenhouse gas emissions inventories - version 2.0. Geneva, Switzerland and Washington, DC, USA. Available at: http://www.ghgprotocol.org/ files/ghgp/GPCDraft 2.0 for public comment.pdf

Soimakallio S et al (2015) Attributional life cycle assessment: is a landuse baseline necessary? Int J Life Cycle Assess 20(10):1364-1375

Suh S, Yang Y (2014) On the uncanny capabilities of consequential LCA. Int J Life Cycle Assess 19(6):1179-1184

Tillman A-M (2000) Significance of decision-making for LCA methodology. Environ Impact Asses 20(1):113-123

United Nations (1992) United Nations Framework Convention on Climate Change. Available at: http://unfccc.int/files/essential background/ background_publications_htmlpdf/application/pdf/conveng.pdf

WBCSD/WRI (2004) Greenhouse gas protocol: a corporate accounting and reporting standard. World Business Council for Sustainable Development and World Resources Institute, Geneva

WBCSD/WRI (2005) GHG protocol for project accounting. World Business Council for Sustainable Development and World Resources Institute, Geneva

WRI (2014a) Greenhouse gas protocol policy and action standard: an accounting and reporting standard for estimating the greenhouse gas effects of policies and actions. World Resources Institute, Washington

WRI (2014b) Greenhouse gas protocol: mitigation goal standard. Washington. Available at: http://ghgprotocol.org/sites/default/files/ ghgp/Mitigation_Goal_Standard_July15.pdf 